\title{
Effect of dislocation configuration on Ag segregation in subgrain boundary of a Mg-Ag alloy
}

\author{
Lirong Xiao ${ }^{a}$, Xuefei Chen ${ }^{b}$, Kang Wei ${ }^{a}$, Yi Liu ${ }^{a}$, Dongdi Yin ${ }^{c}, Z^{2}$ haohua Hu ${ }^{d}$, Hao Zhou ${ }^{a}, *$, \\ Yuntian $\mathrm{Zhu}^{\mathrm{a}, \mathrm{e}, *}$
}

a Nano and Heterogeneous Material Center, Nanjing University of Science and Technology, Nanjing, 210094, China

${ }^{\mathrm{b}}$ Institute of Mechanics, Chinese Academy of Sciences, Beijing, 100190, China

' School of Materials Science and Engineering, Southwest Jiaotong University, Sichuan 610031, China

d Ansteel Beijing Research Institute Co., Ltd., Beijing, 102209, China

e Department of Materials Science \& Engineering, North Carolina State University, Raleigh, NC 27695, USA

\section{A R T I C L E I N F O}

Article history:

Received 19 May 2020

Revised 29 July 2020

Accepted 20 August 2020

Available online 8 October 2020

\section{Keywords:}

Interfacial segregation

Nanocrystallization

Sub-grain boundary

HAADF-STEM

Mg alloy

\begin{abstract}
A B S T R A C T
Interfacial segregation has been reported to play a critical role in the thermal-mechanical stability of nanocrystalline $\mathrm{Mg}$ alloys. Here we report Ag-segregation-assisted formation of nanocrystalline $\mathrm{Mg}$ - $\mathrm{Ag}$ alloy with high proportion of sub-grain boundaries during conventional rolling. The segregation structure is determined by dislocation configurations and subsequent strain field and misorientation of the subgrain boundary. It indicates that the alloying elements, which induce $<\mathrm{c}+\mathrm{a}>$ dislocations, would help to improve the stability of interfaces.
\end{abstract}

(c) 2020 Acta Materialia Inc. Published by Elsevier Ltd. All rights reserved.
Addition of alloy elements can produce considerable solution strengthening [1, 2]. Oversaturated solid solutions may result in high density of nano precipitates, which produces precipitation hardneing [3, 4]. In addition, the interaction between the solute elements and crystal defects may also produce additional strengthening $[5,6]$. Raabe et al. reported an interface-stabilized structure formed by solute element segregation at dislocation cores, which was thought to promote nanocrystallization in an Fe-Mn alloy [7]. Ordered periodic segregation have also been observed on planar structural defects, such as stacking faults (SFs) [8, 9], twin boundaries [10-12], and grain boundaries [13-15]. Interfacial segregation plays a critical role in improving the stability of nano-structures [7, 16-18]. For example, an Mg-Gd-Y-Ag-Zr alloy with grain boundary segregation was stable up to $400^{\circ} \mathrm{C}$, which was much higher than most precipitates in the matrix [19].

It is possible to obtain stable nanostructures by solute segregation to crystal defects during processing [20-23]. Lu et al. produced a nanocarystalline Ni-Mo alloy with a grain size of $\sim 10 \mathrm{~nm}$ using segregation of Mo to grain boundaries [24]. The pinning of crystalline defects by segregated elements can hinder dynamic recovery during plastic deformation, and consequently promote grain re-

\footnotetext{
* Corresponding authors.

E-mail addresses: hzhou511@njust.edu.cn (H. Zhou), ytzhu@ncsu.edu (Y. Zhu).
}

finement, especially for light weight alloys with low melting points [25-27]. Ag has been reported as one of the most promising elements for interfacial segregations in $\mathrm{Mg}$ alloys [11, 28-30]. Feng et al. found that Ag segregation in grain boundary retarded grain growth during extrusion and resulted in further grain refinement of a Mg-Al-Zn alloy [31]. Xiao et al. reported a solute segregation assisted nanocrystallization of $\mathrm{Mg}-\mathrm{Ag}$ alloy during conventional rolling [32]. However, it is still unclear how the Ag atoms interact with defects during processing.

In this work, atomic-scale high-angle annular dark-field (HAADF) technique based on scanning transmission electron microscopy (STEM) was used to investigate the interaction of the segregated $\mathrm{Ag}$ with three typical sub-grain boundaries (SGBs) in a binary $\mathrm{Mg}-\mathrm{Ag}$ alloy. A detailed analysis of local strain and Ag segregation were performed to clarify the formation mechanism of interfacial segregation, which provides insight on nanocrytallization of Mg alloys assisted by solute segregation.

A Mg-Ag alloy with 2.57 wt. \% Ag was cold rolled to a thickness reduction of $\sim 55 \%$, and then annealed at $150^{\circ} \mathrm{C}$ for 15 mins. Samples for transmission electron microscopy (TEM) were prepared in a standard way (see ref. [19]). HAADF-STEM observation was conducted using aberration-corrected TEM. Transmission Kikuchi diffraction (TKD) was performed in a field-emission scanning elec- 

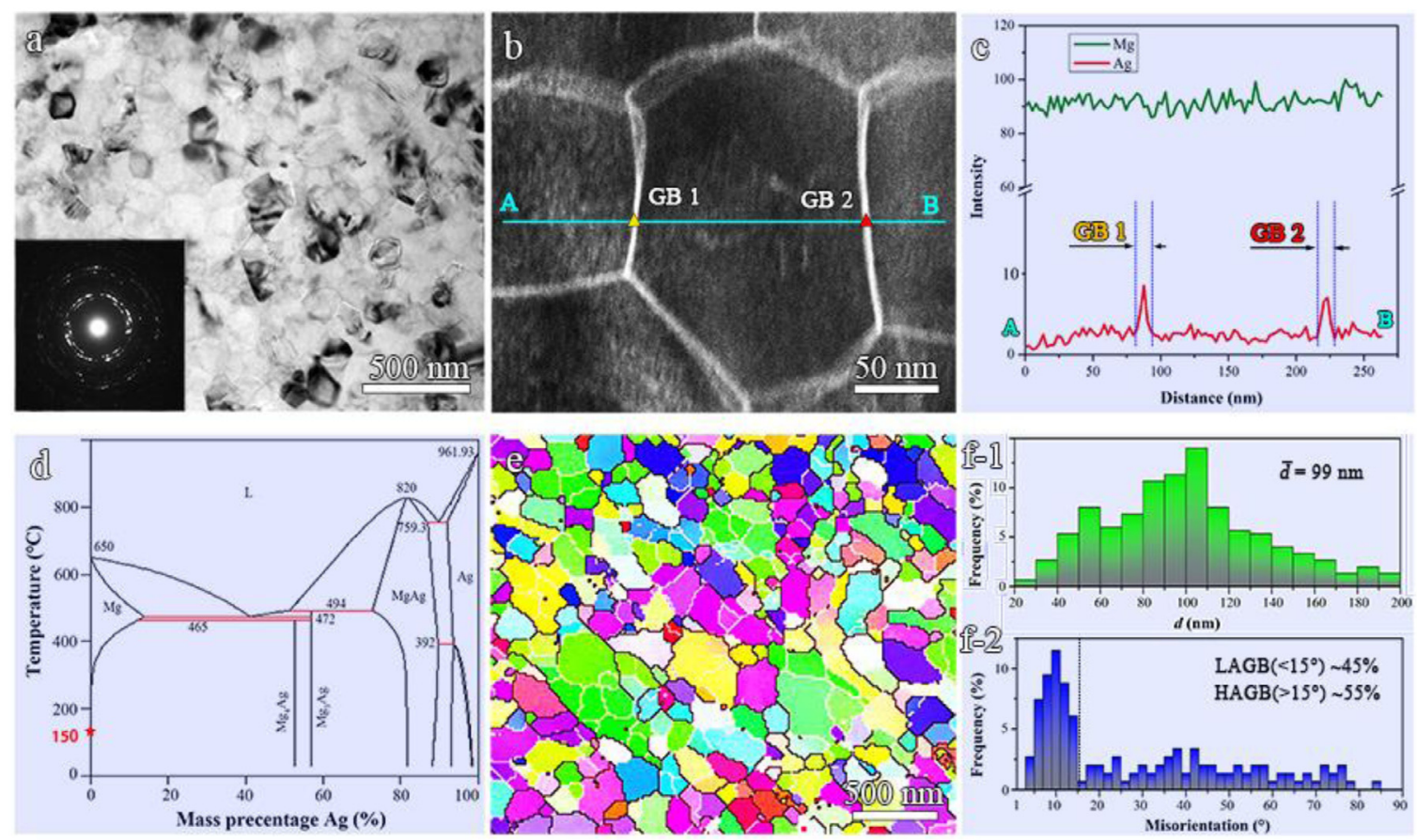

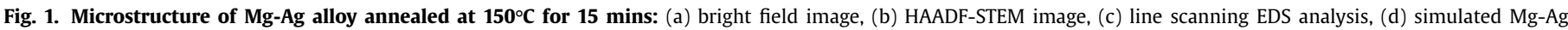
phase diagram, (e) TKD image, (f-1) and (f-2) distribution of grain size and misorientation of (e).

tron microscope. Digital Micrograph plug-in was used for geometric phase analysis (GPA).

Ag provides significant precipitation strengthening in magnesium alloys [33, 34]. Fig. 1a shows that uniform nanocrystallization occurred in the Mg-Ag alloy subjected to only 55\% cold rolling strain. It is usually difficult to produce nanocrystalline $\mathrm{Mg}$ alloys due to their low melting points $[35,36]$. Figs. $1 \mathrm{~b}$ and $\mathrm{c}$ show extensive Ag segregation to the boundaries of nano grains, while few second phases are observed in the grain interior after annealing at $150^{\circ} \mathrm{C}$ for 15 mins.

The driving force for interfacial segregation is illustrated by the simulated $\mathrm{Mg}-\mathrm{Ag}$ phase diagram (Fig. 1d). The solubility of $\mathrm{Ag}$ in $\mathrm{Mg}$ is almost zero at $150^{\circ} \mathrm{C}$, leading to $\mathrm{Ag}$ segregation on interfaces. Uniformly dispersed nano-scale Ag clusters were formed at the cold rolling stage, which were proposed as the precursor of interfacial segregation [32]. Fig. $1 \mathrm{e}$ and $1 \mathrm{f}-1$ show an average grain size of $\sim 99 \mathrm{~nm}$. The statistical analysis in Fig. $1 \mathrm{f}-2$ reveals that the proportion of SGBs $\left(<15^{\circ}\right)$ in the nanocrystalline reaches $45 \%$, which is much higher than that in the nanocrystalline Mg alloys produced by SPD $[37,38]$. It is widely accepted that the formation of SGBs in Mg alloys is related to dislocation accumulation [39, 40]. However, due to its poor thermal stability, the sub-grains are not stable during hot deformation. In this case, Ag rapidly segregated to SGBs, leading to effective grain refinement. Fig. $1 \mathrm{f}-2$ shows that the typical misorientation of SGBs is $\sim 10^{\circ}$.

It is generally accepted that SGBs in Mg alloys are formed by orderly arrangement of dislocations [40, 41]. Depending on dislocation arrangement, three typical SGBs are found in the nanocrystalline $\mathrm{Mg}-\mathrm{Ag}$ alloy. Fig. 2a shows a HAADF-STEM image of the Type I sub-grain boundary (SGBI) viewed from [1120] zone axis. It consists of orderly arranged dislocations along the direction close to the c-axis of the matrix. The angle between SGB (marked by pink dash line) and basal plane is $\sim 90^{\circ}$. Atomic-scale HAADF-STEM and corresponding FFT (Fig. 2a and b) indicate that the SGBI is a tilt boundary along [1120] zone axis, which has a misorientation of $\sim 8^{\circ}$. Fig. 2c-1 shows an enlarged HAADF-STEM image of segregation. Dislocation circuit based on the reference (1100) and (0001) planes revealed a Burgers vector of $1 / 3<1210>$. The interfacial segregation is mostly distributed at dislocation cores, according to the Z-contrast. Figs. 2c-2 and c-3 show the intensity integrations in the directions along and across the SGBI, respectively. At least three typical SGBs of the same type were analyzed and measured. The average width of $\mathrm{Ag}$ segregation is $\sim 1.6 \mathrm{~nm}$ in diameter, and the intensity contrast is $\sim 7$.

Fig. $2 \mathrm{~d}-1$ shows the accurate positions of dislocation cores, as determined by filtering the image with the reflection of (1100) plane, and marked by the green " $\perp$ ". The spacing of dislocation cores is $\sim 2.5 \mathrm{~nm}$, which is close to the spacing of SFs in matrix (Fig. 2d-1). The SFs are proposed as intrinsic $\mathrm{I}_{2}$ faults, because both the $1 / 3<1100>$ Shockley partial and $1 / 3<1 \overline{2} 10>$ perfect dislocations are slipping on the same basal plane [42]. Fig. $2 \mathrm{~d}-2$ shows adjacent extension and compression regions at dislocation cores, as marked by red and blue circles, respectively.

Previous work reported that local stress state had huge influences on the atomic occupation of interfacial segregation [12]. To quantitatively analyze the relationship between local elastic strain and interfacial segregation, GPA strain mappings were performed in Fig. 2a, where the normal directions of (1100) and (0001) planes are defined as $\mathrm{x}$ and $\mathrm{y}$ axes, respectively. Fig. $2 \mathrm{~d}-3$ shows that the distribution of $\varepsilon_{\mathrm{xx}}$ is consistent with that of dislocations and SFs. The positive and negative strains in GPA mapping are related to the tension and compression regions of dislocations, respectively. As shown in Fig. $2 \mathrm{~d}-4$, the maximum positive strain is only $\sim 1.5$, while the negative strain is almost three times higher ( 4.5). Higher negative strain promotes the segregation of $\mathrm{Ag}$, which has a smaller atomic radius than magnesium. In contrast, no additional semi atomic planes are revealed at dislocation cores by filtering the image with (0001) reflection (Fig. 2e-1). The GPA result also reveals that $\varepsilon_{\mathrm{yy}}$ is much smaller than $\varepsilon_{\mathrm{xx}}$, and the local lattice strain at $\mathrm{SGBI}$ in $\mathrm{y}$ axis is close to zero (Fig. 2e-2).

Fig. 3a shows a HAADF-STEM image of Type II sub-grain boundary (SGBII). The interface of SGBII is almost perpendicular to the c-axis of the hcp Mg matrix. The angle between SGB (marked by the pink dash line) and basal plane is nearly $0^{\circ}$. The FFT patterns 

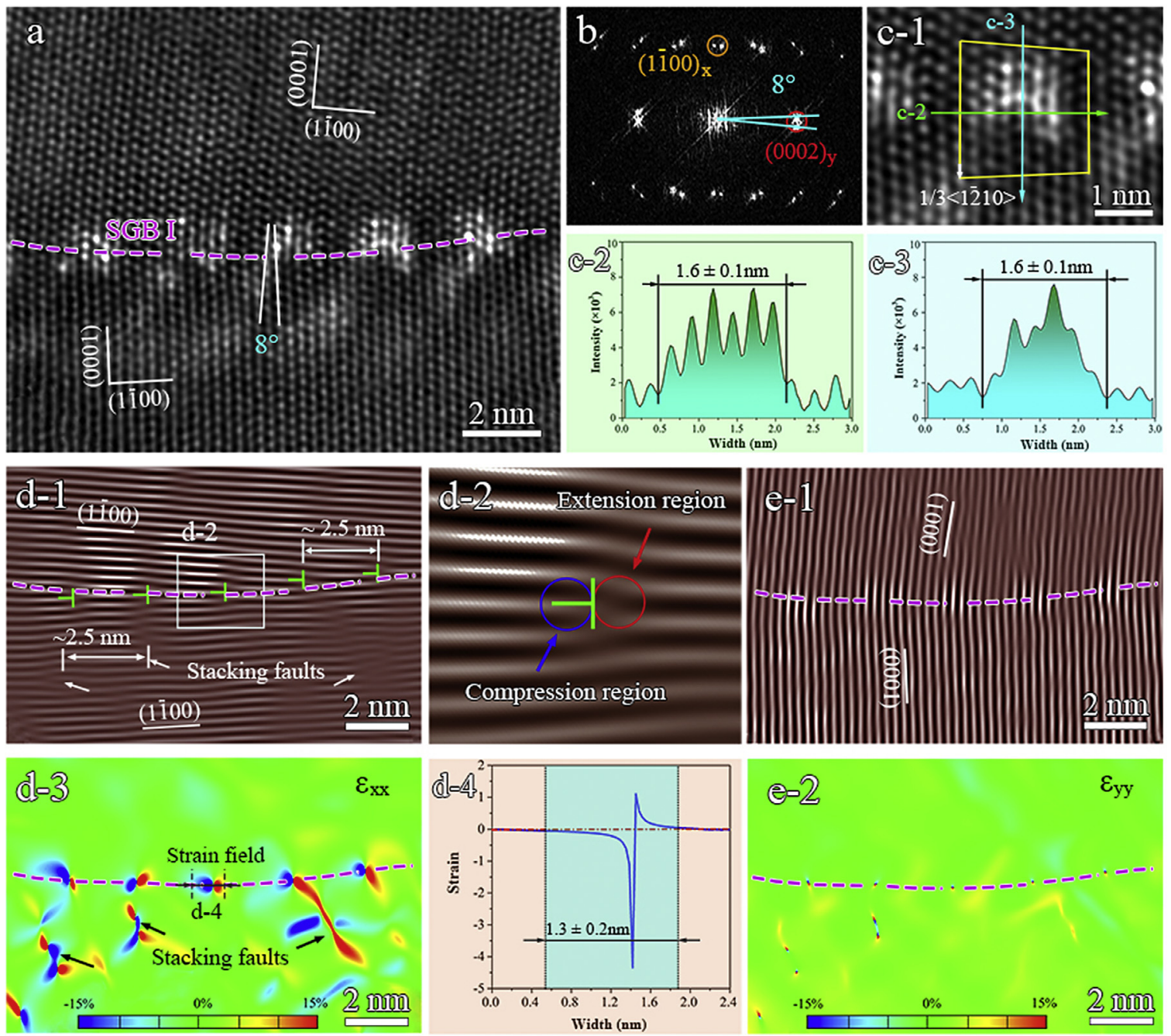

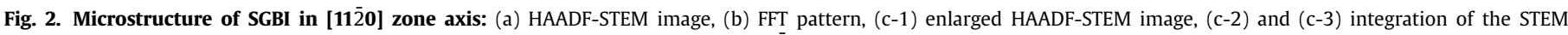

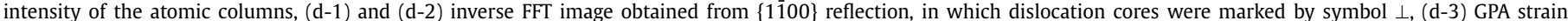

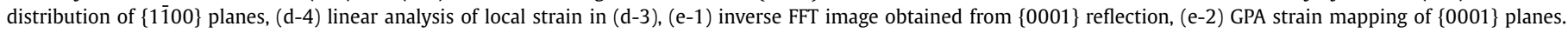

of SGBI and SGBII look the same, in which the lattice is tilted by $\sim 8^{\circ}$ along [1120] zone axis (Fig. $2 \mathrm{~b}$ and Fig. 3b). The structures of SGBI and SGBII are very different because of the different dislocation types. Fig. 3c-1 shows the Burgers vector of dislocations in SGBII as $1 / 6<\overline{2} 20 \overline{3}>$, which corresponds to the bounding partial of $\mathrm{I}_{1}$ faults $[8,43]$. According to Z-contrast, Ag segregation is concentrated in two atomic columns at dislocation cores. Fig. 3c-2 and c-3 show that the area of Ag segregation has a width of $\sim 0.6 \mathrm{~nm}$ in the directions along and across SGBII, which is smaller than that in the SGBI. This is probably resulted from different directions of Burgers vectors of $1 / 3<1 \overline{2} 10>$ perfect dislocations and $1 / 6<\overline{2} 20 \overline{3}>$ partial dislocations. The maximum intensity contrast in SGBII is $\sim 9.5$, which is higher than that in SGBI (Fig. 2c-3). According to the incoherent elastic scattering theory on high-angle electron-nucleus, the intensity of atomic columns in a HAADF image is approximately proportional to the square of the atomic number $Z$ [19]. In this case, the atomic numbers of $\mathrm{Mg}$ and $\mathrm{Ag}$ are 12 and 47, respectively. A higher intensity of contrast indicates a higher volume fraction of $\mathrm{Ag}$ in the atomic column.

Fig. 3d-1 shows dislocation cores determined by filtering the image with (0001) reflection, where there are additional semi atomic planes, as marked by yellow " $\perp$ ". The spacing of dislocation cores is $\sim 2 \mathrm{~nm}$, which is slightly smaller than in the SGBI. Fig. 3d2 shows a pair of tension and compression regions at dislocation cores marked by red and blue circles. The difference is revealed by GPA analysis in Fig. $3 \mathrm{~d}-3$ and d-4. The positive strain of $\varepsilon_{\mathrm{yy}}$ is less than 1 , while the negative strain of $\varepsilon_{\text {yy }}$ reaches $\sim 7$. High negative strain promotes $\mathrm{Ag}$ segregation, because $\mathrm{Ag}$ has a smaller atomic radius $(\sim 0.144 \mathrm{~nm})$ than $\mathrm{Mg}(0.160 \mathrm{~nm})[18,28]$. Moreover, compared with the SGBI (Fig. 2d-4), the width of strain field is reduced to $\sim 0.6 \mathrm{~nm}$ (Fig. $3 \mathrm{~d}-4$ ), leading to a more concentrated Ag segregation in the SGBII. Fig. 3e-1 shows additional semi-atomic planes. However, they are inserted in pairs of "positive-to-negative", rather than in the same direction as in SGBI. GPA strain mappings indicate that the strain in the SGBII has components in both $\mathrm{x}$ and $\mathrm{y}$ axes, but dominated by $\varepsilon_{\mathrm{yy}}$ (Fig. 3e-2).

A third type sub-grain boundary (SGBIII) was observed, which consists of mixed types of dislocations. Fig. 4a shows a HAADFSTEM image of SGBIII. Fig. 4b shows FFT pattern of the SGBIII, which is also a tilt boundary with a misorientation of $\sim 11^{\circ}$. Burgers vector determined by dislocation circuit shows that partial dislocation $(\boldsymbol{b}=1 / 6<\overline{2} 20 \overline{3}>)$ and perfect dislocation $(\boldsymbol{b}=1 / 3<\overline{1} 2 \overline{1} 0>)$ coexist at the position of interfacial segregation (Fig. 4c-1). Fig. 4c-2 and $\mathrm{c}-3$ show that the area of Ag segregation in SGBIII has a diameter of $\sim 1.4 \mathrm{~nm}$. Note that there could be a slight overlap of segregation area owing to the narrow spacing of dislocations, leading to a smaller measured segregation width in Fig. 4c-2. Meanwhile, the maximum intensity contrast in SGBIII is $>9$. Clearly, the interfacial 

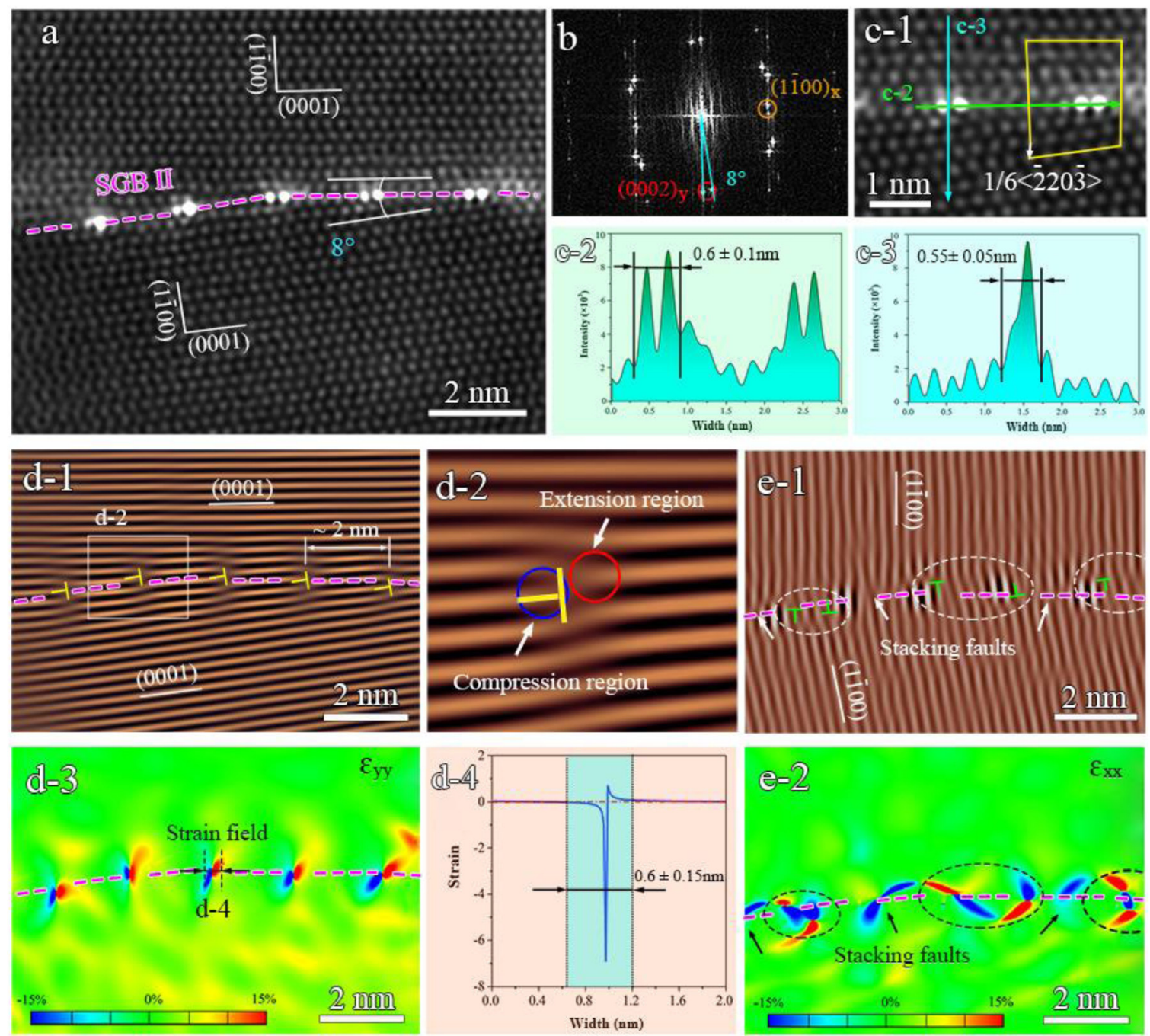

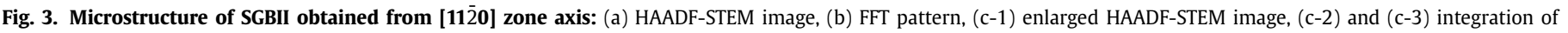

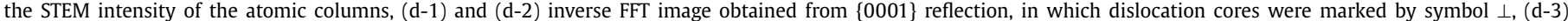

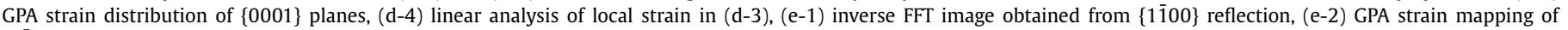
$\{1 \overline{1} 00\}$ planes.

segregation in SGBIII is optimized, which have both a large region and a high intensity. Fig. 4d-1 and e- 1 clearly show the positions of dislocation cores. The perfect dislocations $(\boldsymbol{b}=1 / 3<\overline{1} 2 \overline{1} 0>)$ are marked by the green " $\perp$ ", while the partial dislocations are marked by the yellow " $\perp$ ". The average spacing between dislocations is reduced to $\sim 1.5 \mathrm{~nm}$, leading to a higher density of segregation in the SGBIII. GPA strain mappings in Fig. $4 d-2$ and e- 2 show that the alternatively arranged perfect and partial dislocations induced large regions of negative strain on both sides of grain boundary. The negative strain at dislocation cores are 5 6 (Fig. 4d-3 and e-3). Therefore, a lamellar segregation with a thickness of $\sim 1.4 \mathrm{~nm}$ was formed along the SGBIII.

The interfacial segregation on twin boundary is influenced by atomic radius and interfacial energy [12, 18, 28]. Here $\mathrm{Ag}$ is the sole solute element in Mg-Ag alloy. However, the Burgers vectors and misorientation angles of the SGBI, SGBII and SGBIII are different. According to the Read-Shockley equation [44]:

$\gamma_{b}=\frac{G b}{4 \pi(1-v)} \theta \ln \left(\frac{\alpha e}{2 \pi \theta}\right)$

where $\mathrm{G}, \mathrm{b}, v, \theta$ are the shear modulus, Burgers vector of the edge dislocation, the Poisson's ratio and misorientation angle, respectively. $\alpha$ is a numerical constant and e is the index.
If the sub-grains are composed of the dislocations with the same Burgers vector, the interfacial energy is increased with increasing of misorientation $(\theta)$ [45]. When the misorientation of interface is the same, a larger Burgers vector will lead to a higher interfacial energy. The $|\boldsymbol{b}|$ of $1 / 3<1 \overline{2} 10>$ (SGBI), $1 / 6<\overline{2} 20 \overline{3}>$ (SGBII) and $1 / 6<\overline{4} 6 \overline{2} \overline{3}>$ (SGBIII) are a, 0.996a and 1.656a, respectively [46]. The SGBIII has the highest interfacial energy, because both the $\theta$ and $b$ of SGBIII are highest.

Fig. 4c-1 shows both perfect dislocation and partial dislocation in the SGBIII. The generation of partial dislocations in Mg alloy is related to the activation of $<\mathrm{c}+\mathrm{a}>$ slip system [47]. Therefore, it is proposed to introduce more elements to reduce the activation barrier of $<\mathrm{c}+\mathrm{a}>$ slip to form more SGBIIIs [48]. It is worthy to explore other elements that may help to induce $<\mathrm{c}+\mathrm{a}>$ slip in $\mathrm{Mg}-$ Ag system [49-51].

In summary, a uniform nanograin structure is produced in a $\mathrm{Mg}-\mathrm{Ag}$ alloy by rolling. The thermal-mechanical stability of defects, such as dislocations and grain boundaries, is improved by Ag segregation. The interaction of $\mathrm{Ag}$ with SGBs is studied and the key findings are summarized below:

1. The SGBI $\left(\sim 8^{\circ}\right)$ consists of perfect dislocations with a Burgers vector of $b=1 / 3<1210>$. The average dislocation spacing is 

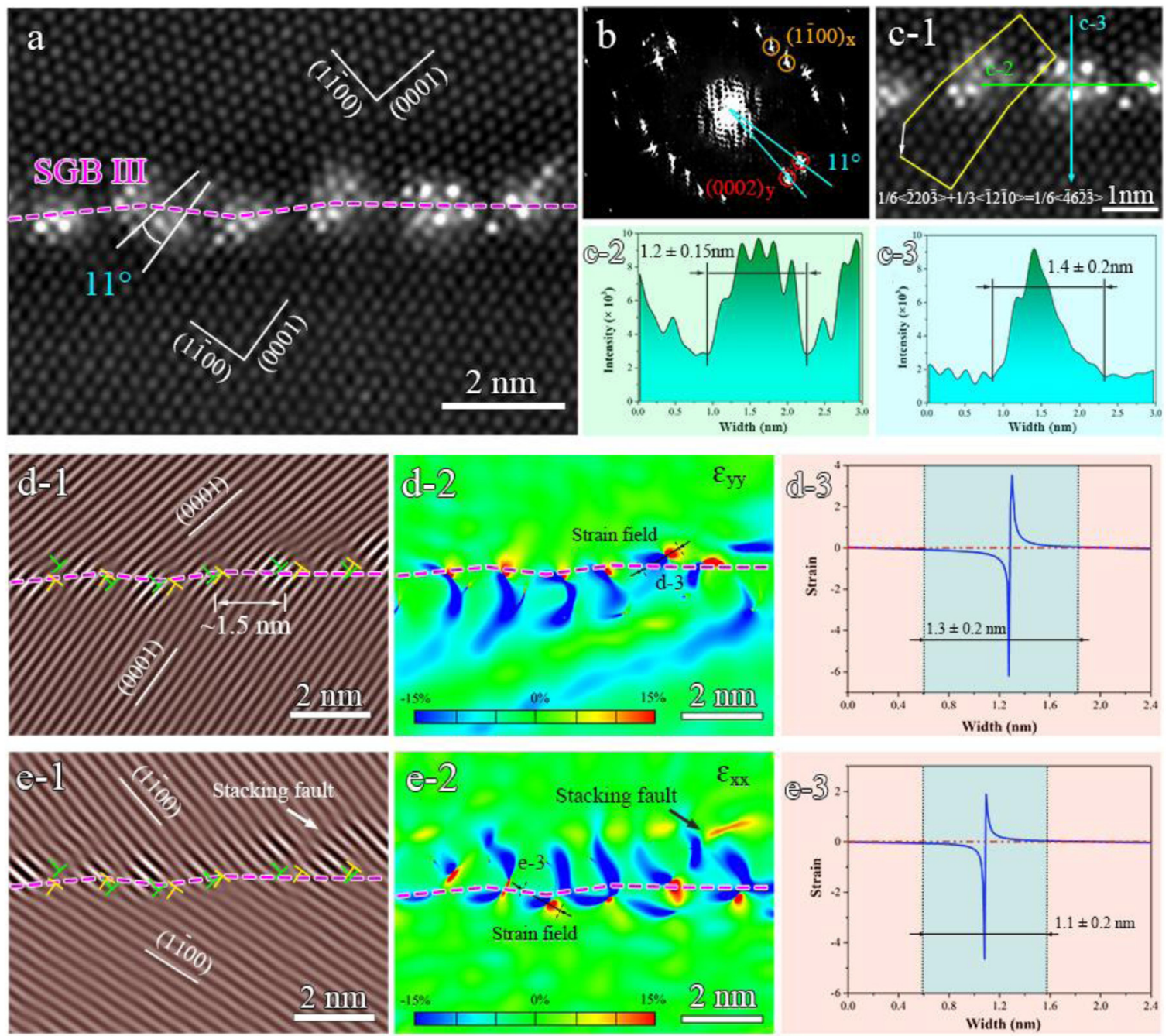

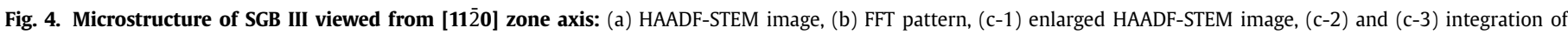

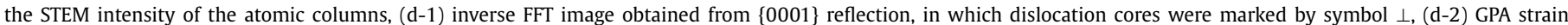

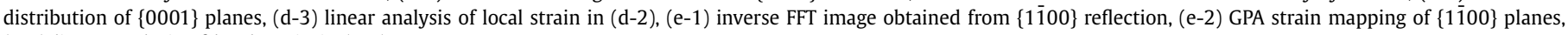
(e-3) linear analysis of local strain in (e-2).

$\sim 2.5 \mathrm{~nm}$. The strain in the SGBI is mainly $\varepsilon_{\mathrm{xx}}$. Interfacial segregation of $\mathrm{Ag}$ is concentrated at dislocation cores. The area of segregation is $1.6 \mathrm{~nm}$ in diameter, and the maximum intensity is $\sim 7$.

2. The SGBII (also $\sim 8^{\circ}$ ) consists of partial dislocations with a Burgers vector of $b=1 / 6<\overline{2} 20 \overline{3}>$. The average spacing of dislocation cores is $\sim 2 \mathrm{~nm}$, which is slightly smaller than that in the SGBI. The strain has components in both $\mathrm{x}$ and $\mathrm{y}$ axes, but dominated by $\varepsilon_{\mathrm{yy}}$. The area of interfacial segregation is $0.6 \mathrm{~nm}$ in diameter, and the maximum intensity is $\sim 9.5$.

3. The SGBIII $\left(\sim 11^{\circ}\right)$ consists of a mixed perfect and partial dislocations. The average spacing of dislocation cores is $\sim 1.5 \mathrm{~nm}$, which is smaller than those in the SGBI and SGBII. Strain components in $\mathrm{x}$ and $\mathrm{y}$ axes are induced by perfect and partial dislocations, respectively, leading to a higher intensity and a larger area of interfacial segregation.

4. The interfacial energy of the SGBIII is much higher than those in the SGBI and SGBII, resulting in the formation of optimized segregation structure. It is suggested to explore additional alloying of Mg-Ag alloy by adding other elements to induce more $<\mathrm{c}+\mathrm{a}>$ dislocations.

\section{Declaration of Competing Interest}

None.

\section{Acknowledgements}

This work is supported by the National Key Research and Development Program of China [2017YFA0204403], the $\mathrm{Na}$ tional Natural Science Foundation of China [51901103, 51931003, 52071178], the Fundamental Research Funds for the Central Universities [30918011342], the China Postdoctoral Science Foundation [2019M661844], The work was also supported by the Jiangsu Key Laboratory of Advanced Micro\&Nano Materials and Technology, and the Materials Characterization Facility of Nanjing University of Science and Technology.

\section{References}

[1] Q. Yu, L. Qi, T. Tsuru, R. Traylor, D. Rugg, J.W. Morris, M. Asta, D.C. Chrzan, A.M. Minor, Science 347 (2015) 635-639.

[2] C. Varvenne, G.P.M. Leyson, M. Ghazisaeidi, W.A. Curtin, Acta Mater 124 (2017) 660-683. 
[3] S. Tang, T.Z. Xin, W.Q. Xu, D. Miskovic, G. Sha, Z. Quadir, S. Ringer, K. Nomoto, N. Birbilis, M. Ferry, Nat. commun. 10 (2019) 1003.

[4] X.C. Sha, L.R. Xiao, X.F. Chen, G.M. Cheng, Y.D. Yu, D.D. Yin, H. Zhou, Philos. Mag. 99 (2019) 1957-1969.

[5] M.P. Harmer, Science 332 (2011) 182-183.

[6] S.J. Dillon, M. Tang, W.C. Carter, M.P. Harmer, Acta Mater. 55 (2007) 6208-6218.

[7] M. Kuzmina, M. Herbig, D. Ponge, S. Sandlöbes, D. Raabe, Science 349 (2015) 1080-1083.

[8] Z.Q. Yang, M.F. Chisholm, G. Duscher, X.L. Ma, S.J. Pennycook, Acta Mater. 61 (2013) 350-359.

[9] T.M. Smith, B.S. Good, T.P. Gabb, B.D. Esser, A.J. Egan, L.J. Evans, D.W. McComb, M.J. Mills, Acta Mater. 172 (2019) 55-65.

[10] Z.L. Wang, M. Saito, K.P. McKenna, L. Gu, S. Tsukimoto, A.L. Shluger, Y. Ikuhara, Nature 479 (2011) 380-383.

[11] X.J. Zhao, H.W. Chen, N. Wilson, Q. Liu, J.-F. Nie, Nat. Commun. 10 (2019) 3243.

[12] H. Zhou, G.M. Chen, W.Z.Xu X.L.Ma, S.N. Mathaudhu, Q.D. Wang, Y.T. Zhu, Acta Mater. 95 (2015) 10-19.

[13] Z.Y. Yu, P.R. Cantwell, Q. Gao, D. Yin, Y.Y. Zhang, N.X. Zhou, G.S. Rohrer, M. Widom, J. Luo, M.P. Harmer, Science 358 (2017) 97-101.

[14] J.P. Buban, K. Matsunaga, J. Chen, N. Shibata, W.Y. Ching, Y. Ikuhara, Science 311 (2006) 212-215.

[15] P.V. Liddicoat, X.Z. Liao, Y.H. Zhao, Y.T. Zhu, M.Y. Murashikin, E.J. Lavernia, R.Z. Valiev, S.P. Ringer, Nat. Commun. 1 (2010) 1062.

[16] M. Bugnet, A. Kula, M. Niewczas, G.A. Botton, Acta Mater. 79 (2014) 66-73.

[17] I. Basu, K.G. Pradeep, C. Mießen, L.A. Barrales-Mora, T. Al-Samman, Acta Mater. 116 (2016) 77-94.

[18] J.F. Nie, Y.M. Zhu, J.Z. Liu, X.Y. Fang, Science 340 (2013) 957-960.

[19] L.R. Xiao, Y. Cao, S. Li, H. Zhou, X.L. Ma, L. Mao, X.C. Sha, Q.D. Wang, Y.T. Zhu, X.D. Han, Acta Mater. 162 (2019) 214-225.

[20] A.J. Detor, C.A. Schuh, Acta Mater. 55 (2007) 4221-4232.

[21] W.T. Xing, A.R. Kalidindi, C.A. Schuh, Scripta Mater. 127 (2017) 136-140.

[22] K.A. Darling, M. Rajagopalan, M. Komarasamy, M.A. Bhatia, B.C. Hornbuckle, R.S. Mishra, K.N. Solanki, Nature 537 (2016) 378-381.

[23] J. Hu, Y.N. Shi, X. Sauvage, G. Sha, K. Lu, Science 355 (2017) 1292-1296.

[24] T. Chookajorn, H.A. Murdoch, C.A. Schuh, Science 337 (2012) 951-954.

[25] T.M. Pollock, Science 328 (2010) 986-987.

[26] E. Nyberg, J. Peng, N.R. Neelameggham, in: Magnesium Technology 2016, John Wiley \& Sons Inc., 2016, pp. 7-8.

[27] Y. Liu, M.P Liu, X.F. Chen, Y. Cao, H.J. Roven, M. Murashkin, R.Z. Valiev, H. Zhou, Scripta Mater. 159 (2019) 137-141.
[28] X.F. Chen, L.R. Xiao, Z.G. Ding, W. Liu, Y.T. Zhu, X.L. Wu, Scripta Mater. 178 (2020) 193-197.

29] J.P. Sun, B.O Xu, Z.O. Yang, H. Zhou, J. Han, Y.N. Wu, D. Song, Y.C. Yuan, X.R. Zhuo, H. Liu, A.B. Ma, J. Alloy. Compd. 817 (2020) 152688.

[30] Y. Liu, X.F. Chen, K. Wei, L.R. Xiao, B. Chen, H.B. Long, Y.D. Yu, Z.H. Hu, H. Zhou, Materials 12 (2019) 01307.

[31] J. Feng, H.F. Sun, X.W. Li, H. Wang, W.B. Fang, J. Mater. Res. 31 (2016) 3360-3371.

[32] L.R. Xiao, X.F. Chen, Y. Cao, H. Zhou, X.L. Ma, D.D. Yin, B. Ye, X.D. Han, Y.T. Zhu, Scripta Mater. 177 (2020) 69-73.

[33] S.H. Lv, X.L. Lu, Y.W. Li, F.Z. Meng, X.R. Hua, Q. Yang, X. Qiu, J. Meng, Q. Duan, Mater. Des. 190 (2020) 108561.

[34] Y.P. Ren, H. Zhao, L.Q. Wang, B. Yang, H.X. Li, S.N. Sun, H.C. Pan, G.W. Qin, J. Appl. Cryst. 51 (2018) 844-848.

[35] H. Zhou, H.Y. Ning, X.L. Ma, D.D. Yin, L.R. Xiao, X.C. Sha, Y.D. Yu, Q.D. Wang, Y.S. Li, J. Mater. Sci. Technol. 34 (2018) 1067-1075.

[36] S.M. Fatemi, A. Zarei-Hanzaki, H. Paul, J. Alloy. Compd. 699 (2017) 796-802.

[37] J.Z. Long, Q.S. Pan, N.R. Tao, L. Lu, Mater. Res. Lett. 6 (2018) 456-461.

[38] K.S. Kumar, H. Van Swygenhoven, S. Suresh, Acta Mater. 51 (2003) 5743-5774.

[39] M.H.F.J. Humphreys, in: Recrystallization and related annealing phenomena, 2nd ed., Elsevier Ltd, Austrilia, 2004, p. 17.

[40] J. Wang, I.J. Beyerlein, C.N. Tomé, Int. J. Plast. 56 (2014) 156-172.

[41] J. Wang, I.J. Beyerlein, Modelling Simul. Mater. Sci. Eng. 20 (2012) 024002

[42] S.Q. Zhu, S.P. Ringer, Acta Mater. 144 (2018) 365-375.

[43] W.W. Hu, Z.Q. Yang, H.Q. Ye, Acta Mater. 124 (2017) 372-382.

[44] E. Rabkin, I. Snapiro, Acta Mater. 48 (2000) 4463-4469.

[45] Peter M. Anderson, J.P. Hirth, J. Lothe, in: Therogy of Dislocations, 3rd ed., Cambridge University Press, New York, 2017, p. 1353.

[46] D.J.Bacon D.Hull, in: Introduction to Dislocations, 5th ed., Elsevier Ltd, Oxford, 2011, p. 111.

[47] Z.X. Wu, W.A. Curtin, P. Natl. Acad. Sci. USA. 113 (2016) 11137-11142.

[48] M.Friák S.Sandlöbes, S. Zaefferer, A. Dick, S. Yi, D. Letzig, Z. Pei, L.F. Zhu, J. neugebauer, D. Raabe, Acta Mater. 60 (2012) 3011-3021.

49] Z.G. Ding, W. Liu, H. Sun, S. Li, D.L. Zhang, Y.H. Zhao, E.J. Lavernia, Y.T. Zhu, Acta Mater. 146 (2018) 265-272.

[50] Z.X. Wu, R. Ahmad, B.L. Yin, S. Sandlöbes, W.A. Curtin, Science 359 (2018) 447-452.

[51] H.S. Jang, B.J. Lee, Scripta Mater. 160 (2019) 39-43. 